\title{
FIFTY CASES OF INNOCENT LARYNGEAL GROWTHS.
}

\author{
By Andrew Wylie, M.D., \\ Surgeon, Central London Throat and Ear Hospital. \\ WITH PATHOLOGICAL REPORT \\ By Wyat' Wingrave, M.D., \\ Pathologist, Central London Throat and Ear Hospital.
}

(Concluded from p. 40.)

These fifty cases supply us with several clinical features, which may be briefly summarised.

Age.-Benign growths attack all ages. We have recorded growths from the age of 4 up to 73 years. No age is exempt, but growths are rare between the ages of 6 and 20 .

Sex.-Both sexes are equally liable.

Occupation is a decided factor. Patients who use their voice daily, such as army officers, singers, teachers, and clergymen are much more liable to laryngeal growths than those whose occupations do not entail speaking or shouting. Hawkers, shouting amid the traffic of the streets, sea-captains in the roar of the gale, and engineers amidst the rattle of machinery are specially liable.

Hereditary Predisposition.--None has been found. No sign of tuberculosis in any case. A history of specific disease was, however, noted in two cases, but the histology afforded no evidence of granulomatous or inflammatory infiltrations.

Type and Habits of Patients.--These are not definitely marked; growths are found in anæmic females and in strong robust men; in thin and in stout people. Nodes and small papillomata are generally found in young girls, especially in those who habitually strain the voice. Smoking seems to have no effect:

Predisposing Causes.-All forms of obstruction or growth in the air-passages of the nose, the nasopharynx or pharynx, such as polypi, enlarged turbinals, deviations and spurs of the septum, adenoid growths and septic tonsils, are predisposing causes.

Two cases (Nos. 47 and 48) were cured by an operation to the nose alone. Several cases were treated successfully by a complete rest to the voice, without any surgical interference.

As already mentioned, two cases had a history of specific disease, and were treated specifically after the growths were removed.

Symptoms. - The usual symptoms were temporary or permanent loss of voice, roughness, hoarseness, and a tired feeling or change in the character of the voice, but in some cases there were no symptoms, and in the others the symptoms were very light. For instance, Case 6 complained merely of an irritating cough, and a large papilloma was found. Case 13 complained of a slight difficulty in speaking. Some cases on the other hand, develop symptoms not directly referable to the larynx. Case 40 suffered from repeated attacks of epistaxis, and a subglottic growth was detected growing from the left vocal cord. The epistaxis disappeared after the growth was removed. There was no alteration of the voice, and no abnormality was found in the nose. 
Vertigo, although attributed to laryngeal growths, was not met with in any of these cases.

Site.-These growths are situated on any part of the larynx: The ventricular bands, the anterior and posterior commissures, but most often on the vocal cords themselves. The ordinary laryngeal growth is generally found on the edge or upper surface of the vocal cord ; sometimes below it. The anterior end and especially the left vocal cord is the favourite situation. In 34 cases the growths grew in the anterior part of the larynx, and of these 21 were on the left cord. Seven cases only at the posterior end of the larynx, and four of these were on the left cord, In 3 cases the growths were situated in the anterior commissure. Cases 7 (Fig. 1), 43 (Fig. 8).

It is unfortunate that so many growths seem to prefer the anterior end of the left vocal cord, as it is much easier to remove them from the right vocal cord, and especially from the posterior end of that cord.

Origin.-Benign growths develop in a simple manner. A mouthbreather or individual with some nasal obstruction obviously strains one or both vocal cords when singing or shouting. This leads to hyperæmia and rupture of minute vessels, and interstitial extravasation of bloodLater this develops into a localised hypertrophy, and subsequently a papilloma, fibroma, or angioma is seen with the laryngoscope.

Treatment.-The chief aim of the laryngologist is to remove the growth or growths as cleanly as possible without leaving any portion behind or causing any injury to the vocal cord or part of the larynx where the growth is attached.

There are exceptions when surgery is superfluous. For instance, in children suffering from a papilloma or even multiple papillomata, complete rest may ensure a cure. Sometimes temporary tracheotomy has to be performed if the child sulfer from dyspncea or other serious complication.

Removal.--There are two methods of removing laryngeal growths: the direct and indirect methods.

The direct method has many adherents, and is useful in nervous patients and in infants, who both need a general anæsthesia. It is easier to grasp the growth by the direct method, and so perhaps to more thoroughly remove it, especially if situated in the anterior part of the larynx or the anterior commissure.

By direct laryngoscopy the larynx and epiglottis are often injured by the tube, which may cause subsequent pain and discomfort.

We consider that direct laryngoscopy should only be employed when the indirect method fails, as the great majority of growths can be easily removed by the latter.

The indirect method is a simple operation for one's consulting-room, and was employed in 45 cases by laryngeal forceps, by snare, and by galvano-cautery.

Laryngeal Forceps are of several varieties, and each one suitable to its own type of case. MacKenzie's forceps succeed in most cases, especially if the growth be. situated on the upper surface of the cords, or towards the posterior end of the larynx. Grant's forceps are specially fitted for growths on the edge of the vocal cords, but what we call the " universal forceps," viz. a Krause cutting-blade attached to a universal handle is applicable to all kinds of growth. This instrument is light, absolutely steady, easily manipulated, and does not obstruct the view as other forceps do.

The operation has occasionally to be repeated after a week's rest and 
sometimes it is advisable, if a small tag is left, to use a fine-pointed galvano-cautery to destroy it.

The Laryngeal Snare was used in Cases 19, 37, and 40. This instrument removes pedunculated and subglottic growths with little pain and no hæmorrhage. It is easily manipulated when the larynx is well anæsthetised, but as the majority of laryngeal growths are somewhat sessile and friable, its use is limited.

The Galvano-Cautery is applied to a laryngeal growth by means of a long, fine platinum point. A special instrument was made for us (Lancet, November 23, 1907).

The larynx must be well cocainised, and a suture inserted through the epiglottis to steady the parts. The cautery is very useful when a small part of the growth is left after an operation with the forceps, or when the growth is an angioma or cystoma.

Several years ago we advocated this method of removal (Lancet, November, 1907), but with more experience, serious drawbacks were found. For instance, the galvano-cautery, in several cases, caused swelling, œdema, and ulceration, and in one case marked dyspncea. It was applied in 10 cases. In Cases $43,44,46$, and 50, with marked success; one case appeared to be an angioma, and the other three very small growths. In Cases 16 and 42 the growths were first removed with Grant's and Whistler's forceps, and a few days later the galvanocautery applied to destroy a minute remaining part. In Cases 18, 38, 39 , and 41 there were such serious after-effects as dyspnœa, dysphagia, and prostration, that we consider the treatment too severe.

Another serious drawback to the galvano-cautery is that it does not admit of post-operative demonstration of the part removed, for an early stage of epithelioma might be diagnosed as benign until too late for satisfactory radical removal.

Results of the Treatment. - Thirty-eight cases were cured within a few weeks; in 6 cases the growths recurred, in 1 case several times; but all were ultimately cured.

Within the last twelve months we have examined 46 of these cases. Thirty-nine were perfectly well; 7 had some thickening and cicatricial tissue, which interfered to a certain degree with proper phonation. Four cases could not be traced.

The removal of laryngeal growths with instruments, "per vias naturales" is simple, but certain details must be practised. Patients must be drilled in the art of holding the tongue and breathing quietiy and steadily. Considerable help can be given by the patient steadying the larynx with the left hand. The epiglottis should have a suture inserted through it with Horsford's needle and pulled gently forwards, Potassium bromide is prescribed several days previous to the operation so as to relieve the mental strain and lessen nervous excitability. A quiet room, good reflected light, and plenty of time and patience are essential. Thorough anæsthesia of the pharynx and larynx is most important. In the first place, the pharynx and larynx is sprayed with a 10 per cent. freshly prepared solution of hydrochlorate of cocaine, then a few drops are inserted direct on to the growth with a syringe, or a solution of cocaine (alkaloid) in olive oil is used. This subdues the irritating cough. (Wingrave.) voice.

After Treatment.-This consists merely of absolute rest to the 
[Harch, 1918.

\section{Remarks by Dr. Wyatt Wingrave.}

The writer published in the Journal of Laryngologr, Rhinology, AND ОтоцоGy, May, 1906, an analysis of the structure of 50 cases of innocent laryngeal growths. That included three removed by Dr. Andrew Wylie. To these are now added 39 specimens, which Dr. Wylie has since submitted for examination, making a total of 42 cases from him.

Histologically the specimens fall into four distinct groups, intowhich they are somewhat arbitrarily divided, according to their predominant structural elements.

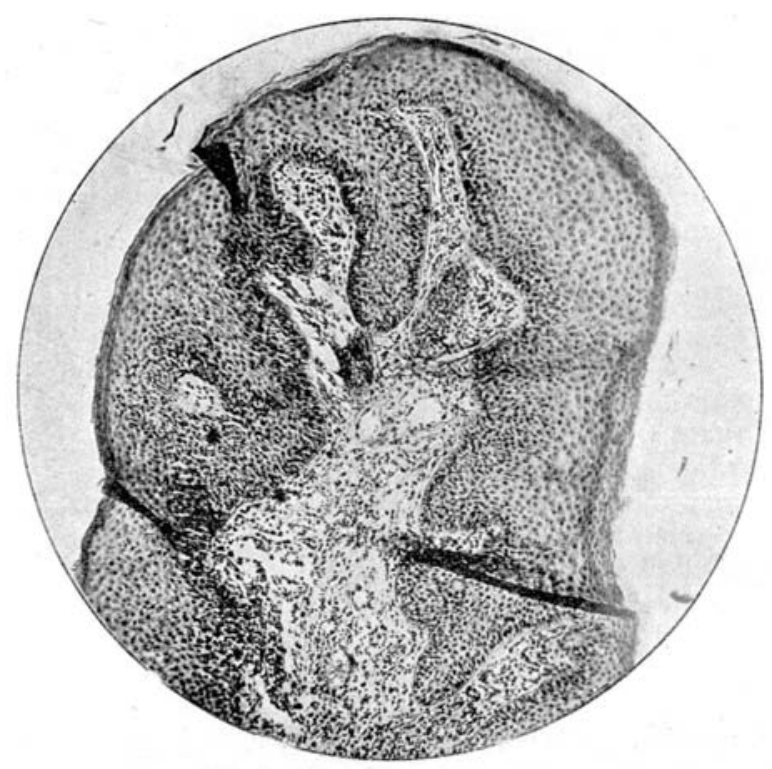

Fig. 10.- Shows one fimbria of a typical papilloma with scanty core.

(1) Fimbriated papillomata or true warts.

(2) Fibro-papillomata.

(3) Fibromata (firm).

(4) Serœdematous fibromata (soft).

(1). The first group or true warts shows a small proportion of fibrovascular core, enclosed in a very thick layer of stratified epithelium, which is always columnar at its deepest part, becoming gradually more flattened as the surface is reached. In most specimens nuclei are present in all the layers, but in a few which have undergone "horny" changes, the surfaces are found densely packed and devoid of nuclei. These are "keratin" cells, and form laminated " pearls" or nests, often seen in the skin and exposed regions, but rarely on moist or mucous. surfaces. When the larynx shares in a general keratosis of the throat, these horny excrescences are very striking, and may bo the seat of various bacterial flora, but micro-organisms were generally absent in the cases under discussion.

The multiple form did not differ in their structure from the solitary.

(2) In the second group the core is relatively in excess, and the: 
surface epithelium much thinner, although thicker than on a normal cord. They do not present such deep fimbriation, being almost smooth to the naked eye. Blood-vessels are very thin, and pigmentation often presents the result of past extravasation of blood-ruptured vessels. It is more like exaggerated corrugation than a true wart, or may even be echinoid in appearance.

(3) The third group is somewhat different. It is generally small, sessile, and firm in consistence. Although thickened, the epithelium exhibits but slight deviation from the normal, but beneath it, instead of elastic fibres, there are only densely-packed colloid or white fibrous tissue bundles with few blood-vessels.

(4) In the fourth group, serœdematous tissue predominates, presenting

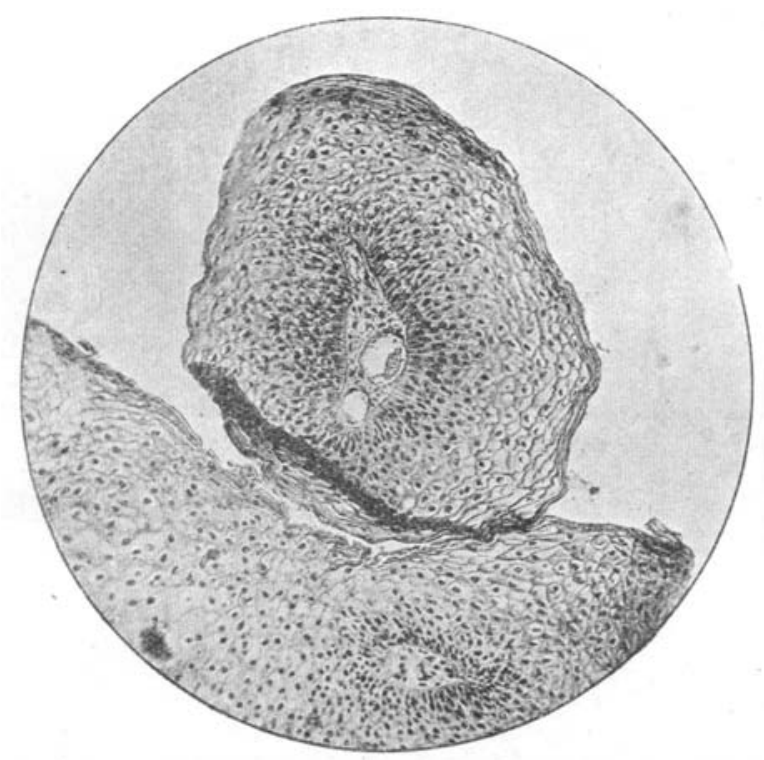

Fia. 11.-A transverse section of a similar growth under a higher power. It shows the central blood-vessels.

the characters of an ordinary polypus, commonly, but incorrectly, called myxomatous. Chemically, there is no mucin as was once supposed. The framework or stroma is very loose, with but scanty elastin, considerable dilation of lymph spaces, and marked thinning of the arteries and veins, whose walls have lost their elastic fibres. It is, therefore, not surprising that they are often ruptured, and interstitial hæmorrhage common. Small vascular thrombi are often seen, together with free and enclosed pigment granules, derived from the blood. This feature is sometimes found in so-called " singer's nodes."

In considering the pathogeny of these growths, much will depend on their site and structure. It may be urged that to call them neoplasms is not quite accurate, for many are simply due to a localised hypertrophy of the normal tissue. The presence of old or recent clots and endovascular thrombi is strongly suggestive of an exciting traumatism, followed by serœedematous changes and pigmentation, occurring in 
a structure which has less than its normal elastic support. While the dense fibroid type may be the result of chronic irritation, in which

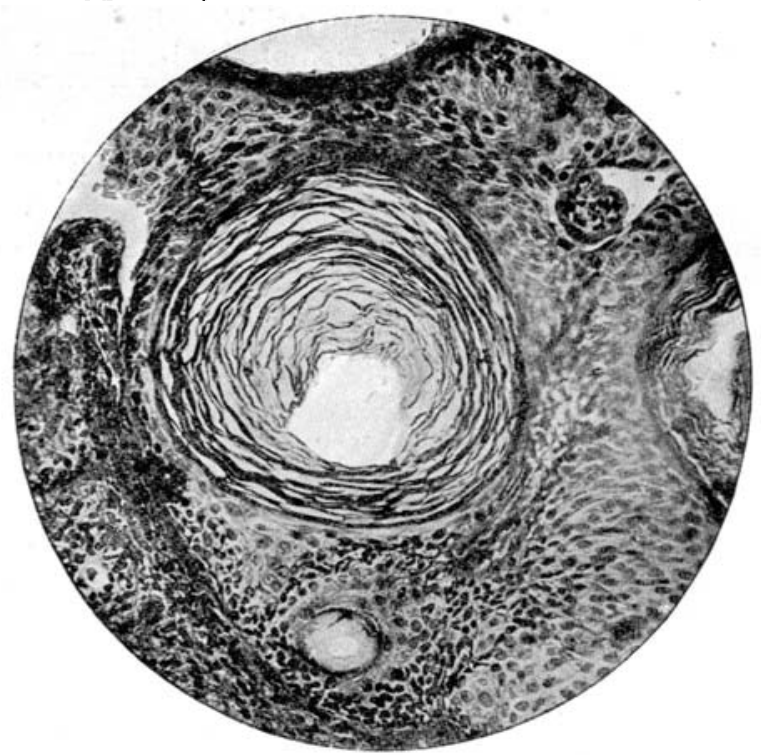

Fra. 12.-Shows several typical " pearls or nests," which consist of laminated dead epithelium containing keratin granules.

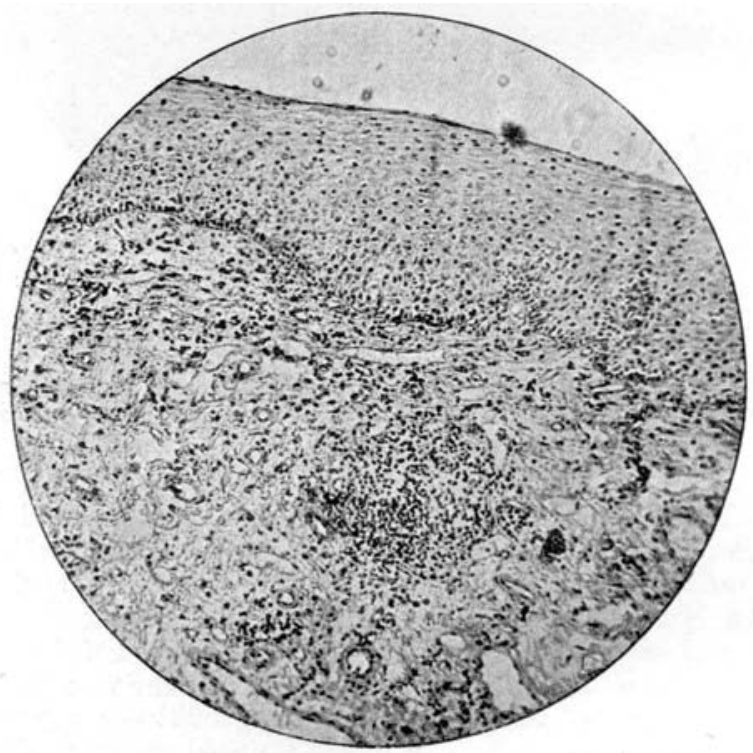

Fig. 13. - Shows plasma cells infiltration, which may be due to a past sepsis, or to irritation in any of the types.

fibrosis follows inflammatory or endothelial cells deposit. The origin of 'warts here may be the same as elsewhere, but there are two features 
which are peculiar to the region: (1) Its special liability to irritation; its vulnerability, both vocal and respiratory. (2) The development of the glottis, in which the anterior commissure may assume the shape of a erescent or web. This normally undergoes suppression, but any interference may result in its but partial disappearance, followed by the persistence of vestiges or "tags." The not infrequent occurrence of multiple papillomata during infancy in this area is certainly significant, in there not having been opportunities for functional shortcomings.

The large amount of fibrous tissue attended by the characteristic red plasma cells and copper-coloured clasmatocytes (when stained by pyronin-green) is very strong evidence that some inflammatory process has been responsible for the hypertrophy, or, at all events, has played a prominent part in its origin. But there is one feature which is peculiar to this region in the varieties except the true warts, viz. thrombosis. This, together with pigmentation (hæmaturic) and absence of elastin, may in a measure be responsible $f$ or the extensive and permanent seroedema. These morphological changes, and what may be termed functional traumatism, are together sufficient to explain the remarkable frequency of many of these local excrescences. Interstitial hæmorrhages with incomplete absorption is the basis of many so-called "singer's nodes."

\title{
WAR INJURIES AND NEUROSES OF OTOLOGICAL INTEREST. ${ }^{1}$
}

\author{
By Dr. C. E. Jones-Phillipson,
}

Late Medical Officer in Charge, Ear, Throat, and Nose Department, Third Army No. 12 Stationary Hospital, British Expeditionary Force.

I HOPE I may be permitted a few rrmarks as one who has looked after the ear cases for the Third Army, having been doing that work for nine months. I had the good fortune to be located at Stationary Hospital No 12, where the Surgeon-General concentrated ear work, allocated forty-four beds (indoor), and gave out-patient accommodation for eighty. All the work of the Third Army was passed through this Department, and I made notes of 1172 cases exumined during that period. As will be seen from the abstract $I$ analysed 100 cases of war injury of the ear, in which there were thirty-one cases of lacerations. I saw all my cases within twenty-four to thirty-six hours of their coming out of the trenches, some on the day of receiving the wound. A previous speaker, and a part of the President's address, laid no particular stress on the site of the laceration, but from my cases I regard that as very significant. In thirty-one cases the laceration occurred in the anteriorinferior quadrant in twenty; in the postero-inferior quadrant in six; in the inferior quadrants-i.e. between the two-in one; in the umbo in two ; in the posterior quadrants across tle two in one; in the anterosuperior quadrant in one. It has also been asked whether any note bad been made of rupture of the membrana flaccida. I had such a case, which is noted under the head "blood in the middle ear." No. 31 had a ruptured membrana tympani in the antero-superior quadrant, high up. There was a slow oozing of sero-sanguineous discharge for several days. Patient went to the base shortly after, and I thought it possible he had

1 Paper read at Meeting of Royal Society of Medicine, Otological Section, February 16, 1917. 